\title{
Application of the variability-size relationship to atmospheric aerosol studies: estimating aerosol lifetimes and ages
}

\author{
J. Williams ${ }^{1}$, M. de Reus ${ }^{1}$, R. Krejei ${ }^{2}$, H. Fischer ${ }^{1}$, and J. Ström ${ }^{2}$ \\ ${ }^{1}$ Max Planck Institute for Chemistry, Mainz, Germany \\ ${ }^{2}$ Institute of Applied Environmental Research (ITM), Stockholm University, Sweden
}

Received: 12 October 2001 - Published in Atmos. Chem. Phys. Discuss.: 18 January 2002

Revised: 2 May 2002 - Accepted: 22 May 2002 - Published: 12 June 2002

\begin{abstract}
Aerosol variability is examined as function of particle size for data collected over the Northern Indian Ocean in February 1999 as part of the INDOEX experiment. It was found that for particles believed to be of terrestrial or oceanic origin, the variability correlated with the average number concentration. For particles that are thought to be formed and grow in the atmosphere through coagulation and condensation an anticorrelation was observed, the minimum in variability coinciding with the maximum in the number concentration. Three altitude ranges were examined $(0-1,4-8$ and $8-13 \mathrm{~km}$ ) and the minimum in variability was found to occur at lower particle sizes in the free troposphere $(0.065 \mu \mathrm{m})$ than in the boundary layer $(0.165 \mu \mathrm{m})$. The observed variability has been compared to that generated by a numerical model in order to determine the relative importance of the physical processes. Modelled variability of $0.02 \mu \mathrm{m}$ particles caused by nucleation was not observed in the measurements. A previously derived empirical relationship for aerosol residence time was compared with the measured variability as a function of bin size. The aerosol variability / residence time relationship was characterised by a coefficient $(b)$ at all altitudes and for both correlating and anticorrelating regimes. By combining the derived coefficient with the model predicted lifetime for $0.020 \mu \mathrm{m}$ particles we estimated residence times and ages as a function of particle size and altitude. General agreement was found with previous estimates of aerosol residence time. In the upper atmosphere aerosols of $0.065 \mu \mathrm{m}$ in size have residence times of approximately 1 month and can be transported on a hemispheric scale. The same size aerosol has a lifetime one order of magnitude less in the boundary layer and therefore will not be transported far from the source regions.
\end{abstract}

Correspondence to: J. Williams

(williams@mpch-mainz.mpg.de)

\section{Introduction}

Aerosols play a key role in the atmosphere and have been the focus of intensive investigation in recent years as they are known to be important components of both urban haze and acid rain (Graedel and Crutzen, 1993; Kulshrestha et al., 1999). When high concentrations of aerosols are widespread, they can have a significant affect on global climate (Charlson et al., 1992; Ramanathan, 1998), directly by scattering and absorbing incoming solar radiation, and indirectly by acting as cloud condensation nuclei for cloud and fog droplets, thereby affecting the droplet concentrations, optical properties and lifetimes of clouds (Houghton, 1996).

The sources of aerosols to the atmosphere may be nominally divided into two types. Those that originate at the Earths surface such as soil dust, sea salt, burning smoke and pollen, and those formed in the atmosphere in situ by chemical reactions or physical processes. Particles are thought to form in the atmosphere mainly out of sulfuric acid and water vapor (Jaeoker-Voirol and Mirabel 1989; Kulmala et al., 1998), however other gases are proposed to play an important role as well, for example ammonia, (Korhonen et al., 1999) and the reaction of ozone with alkenes (Koch et al., 2000). Physical processes, such as mixing and convection may enhance particle formation (Clarke et al., 1998; de Reus et al., 2000, 2001). With time, small particles grow by coagulation and vapour condensation to become larger particles. Eventually they become so large that they fall from the atmosphere by gravity or are scavenged by clouds and precipitation. In the boundary layer the aerosol particles may also impact on obstacles (trees, buildings etc.) or the surface. Aerosols, which can range in size over 7-8 orders of magnitude, are typically measured within narrow size ranges (henceforth termed bin size) which are defined by the geometrically averaged diameter over the range of sizes in this bin. 
The use of measurement variability in the analysis of atmospheric processes was first quantitatively applied to measurements of long lived gas phase species using relative standard deviation (RSD), by Junge (1974). A modified version of this technique using the standard deviation of the natural $\log$ of the concentration (sigma $\ln \mathrm{X}$ ) has recently been successfully employed with trace gas data, to analyse sourcesink relationships, to check data quality, determine the remoteness of a dataset from sources and even estimate radical concentrations (Jobson et al., 1998, 1999; Williams et al., $2000,2001 \mathrm{~b}$ ). The former work is based on the premise that measured variability is to some extent inversely proportional to residence time. Gas phase species in model and measurement studies have been shown to exhibit a variability lifetime relationship which is stronger when the measurements are remote from sources (Erhart et al., 1998; Jobson et al., 1998).

Application of a variability lifetime analysis for aerosol measurements is complicated by the fact that the lifetime of an individual aerosol particle within a size range is difficult to determine; as it is a function of the whole aerosol size distribution. If an aerosol particle changes size then its lifetime will change. It is also possible to have sources or sinks of aerosols which effect only a few bin sizes. This is normally not the case for the gas phase variability analysis where a common sink, usually the hydroxyl radical, predominates for all species. In the first part of this study, the aerosol variability and particle concentration are plotted as a function of particle diameter. If a physical process such as coagulation or condensation causes particles to grow from one bin size to the next, then that process acts as the sink for the smaller aerosol size bin but also as the source for the next highest size bin. This has the advantage that a trend in the variability-size relationship may occur when common physical processes act on aerosols over a wide size range. Although a wide range of aerosol data as a function of size exist (Raes et al., 2000 and references therein) little attention has been given to the lifetimes of aerosols within these size bins since the pioneering work of Jaenicke summarized in Jaenicke (1982).

In this study we present airborne observations of aerosol size distributions between $0.020 \mu \mathrm{m}$ and $2.5 \mu \mathrm{m}$ diameter for the INDOEX campaign, which was based in Male $\left(4.1^{\circ} \mathrm{N}\right.$, $73.3^{\circ} \mathrm{E}$ ) on the Maldives. For various subsets of the data from this campaign, we compare average number concentrations for the logarithmically increasing bin sizes to the measured variability (sigma $\ln \mathrm{X}$ ) of each bin. The relationship of variability to particle size is presented and interpreted in a variety of defined atmospheric conditions and altitude ranges. We analyse measured variability of the particle concentrations in combination with variability derived from numerical simulations of aerosol transformation in order to deduce dominant processes influencing the particle size distribution. Finally we use the measurement variability to empirically derive residence time as a function of particle size for a variety of conditions including the marine boundary layer and sections of the free troposphere.

\section{Instrumentation}

Aerosol size distribution measurements, ranging from 0.020 to $2.5 \mu \mathrm{m}$ diameter, were performed by the Institute of Applied Environmental Research, Stockholm, Sweden, using a combination of instruments. Ambient air is drawn to the aerosol detection instrumentation through a $6.35 \mathrm{~mm}$ rearward facing stainless steel inlet at a rate of $10 \mathrm{~L} \mathrm{~min}^{-1}$. Sampling losses by sedimentation and impaction inside the tubing were calculated as being insignificant due to the submicron sampling by the inlet. Diffusion losses within the inlet are calculated as around $15 \%$ for $7 \mathrm{~nm}$ particles and $10 \%$ for $10 \mathrm{~nm}$ particles (Hinds, 1982). Particles larger than $1 \mu \mathrm{m}$ diameter are not sampled through this inlet due to inertial separation, which prevents these particles from entering the probe (Schröder and Ström, 1997). This inlet is used for Condensation Particle Counters (CPC's) and the Differential Mobility Particle Sizer (DMPS) system. A second, near isokinetic inlet which is able to collect larger particles, facing the flight direction is used by the Optical Particle Counter (OPC).

Between 0.020 and $0.15 \mu \mathrm{m}$ diameter, the particle size distribution is determined using a DMPS system. This instrument is custom built for airborne measurements and has a closed loop sheath air system (Jokinen and Mäkelä, 1997). The DMA used was a short Hauke type, with a sheath airflow of $5 \mathrm{~L} \mathrm{~min}^{-1}$. Particles in a narrow size range selected by the DMA (Differential Mobility Analyzer) were counted by a TSI $3010 \mathrm{CPC}$, with a sample flow rate of $1 \mathrm{~L} \mathrm{~min}^{-1}$. Every $20 \mathrm{~s}$ one scan over ten size bins was performed, which corresponds to a spatial resolution of about $3 \mathrm{~km}$. One minute averaged size distributions were used for the analyses in this paper.

An Optical Particle Counter (OPC) Particle Measuring System Passive Cavity Aerosol Spectrometer Probe (PMS PCASP) was used to determine the particle size distribution of particles with a diameter between 0.12 and $2.5 \mu \mathrm{m}$. This instrument classifies particles in 32 size bins by using the light scattering properties of the aerosols. For the presentation in this paper several bins are combined in order to reduce the uncertainty due to counting statistics. For the smaller particles, $<1 \mu \mathrm{m}$ diameter, the OPC is calibrated using ammonium sulphate particles. For larger particle sizes latex spheres are used. The data were stored at $1 \mathrm{~Hz}$.

The uncertainty in the measured particle number concentrations in the different size bins is dependent on counting statistics, and equal to the square-root of the number of particles counted in a sampling period. Hence, the uncertainty decreases with increasing particle number concentration and averaging time. Only measurements on isobaric flight levels are included in the analysis, since the DMA instrument requires a relatively constant operating pressure. Presented here are the data from DMA and OPC instruments covering particle sizes $0.02-2.5 \mu \mathrm{m}$. Particle size is given as the diameter throughout. 


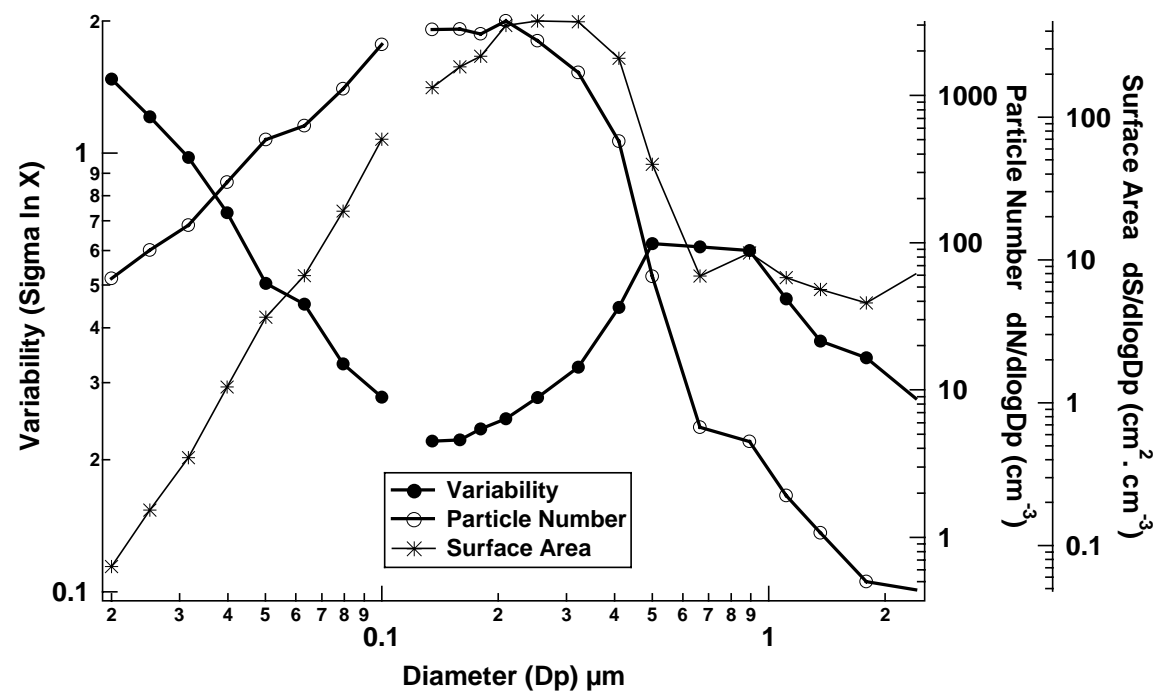

Fig. 1. Measurement variability, average particle number and surface area are plotted as a function of bin size for data collected in the boundary layer $(0-1 \mathrm{~km})$ during the INDOEX campaign.

\section{Results}

\subsection{Variability and size distribution}

The variability to particle size relationship has been examined in data from the Indian Ocean Experiment (INDOEX) experiment. The dataset was collected in February during the winter monsoon, from a base on the Maldive Islands $\left(4.1^{\circ} \mathrm{N}\right.$, $73.3^{\circ} \mathrm{E}$ ) using a Cessna Citation jet aircraft. Measurements were performed between 0.2 to $13 \mathrm{~km}$, over the area $8^{\circ} \mathrm{N}-$ $8^{\circ} \mathrm{S}$ and $70-80^{\circ} \mathrm{E}$. Meteorological conditions over the Indian Ocean are associated with the migration of the Inter Tropical Convergence Zone (ITCZ). Detailed analysis of the prevailing meteorological conditions during the INDOEX campaign is described elsewhere (Verver et al., 2001). The boundary layer over the Maldive Islands is influenced by north-easterly winter monsoon winds which advect polluted air from south-east Asia and the Indian subcontinent, over the Indian Ocean, towards the ITCZ. After entrainment into strong convection, air mainly detrains above $8 \mathrm{~km}$ and returns northwards at various altitudes leading to a complex vertical structure as described by the Hadley circulation model (McGregor and Nieuwolt, 1998; Iyengar et al., 1999). Distinct layers, evident in $\mathrm{CO}$ and $\mathrm{CO}_{2}$ profiles near to the ITCZ at approximately the same latitude, have been previously reported by Williams et al. (2001a).

It has been shown that the atmosphere over the Indian Ocean can be divided into vertical sections with similar trace gas and aerosol characteristics (de Reus et al., 2001). The boundary layer (ca. $0-2.5 \mathrm{~km}$ ) over the northern Indian Ocean was found to contain ubiquitously high trace gas and aerosol concentrations transported by the northeasterly trade winds from South East Asia, (Lelieveld et al., 2001; Williams et al., 2002; de Reus et al., 2001). Between 4 and $8 \mathrm{~km}$ the air had mostly not been in contact with pollution sources for the past 5 days although occasional incidences of outflow from the sides of convective towers were observed at these altitudes. The main outflow of these convective events occurred above $8 \mathrm{~km}$, bringing polluted boundary layer air to the middle to upper free troposphere.

Figure 1 shows the average aerosol size distribution from all scans made in the mixing layer $(0-1 \mathrm{~km})$ within the boundary layer during February. Also shown is the variability of each bin size within this subset of scans. The particle size distribution (open circles) shows a main mode at approximately $0.17 \mu \mathrm{m}$, and a smaller mode at approximately $1 \mu \mathrm{m}$. The size distribution of the variability (solid circles) shows a local minimum at $0.16 \mu \mathrm{m}$ but a local maximum at $1 \mu \mathrm{m}$. For this $0-1 \mathrm{~km}$ dataset, the variability anticorrelates with the number concentration for size bins between $0.02 \mu \mathrm{m}$ and $0.5 \mu \mathrm{m}$ but appears to correlate from $0.5 \mu \mathrm{m}$ to $2.5 \mu \mathrm{m}$. Moreover the variability data exhibits a uniform decrease between 0.020 and $0.15 \mu \mathrm{m}$.

We interpret the uniform decrease in variability observed between $0.02-0.15 \mu \mathrm{m}$ as indicating that a common growth process is predominant over successive size bins, and that with increasing size it takes longer for an aerosol of given size to grow into the next size bin. Based on previous work in the marine boundary layer we assume this process to be coagulation, which acts a source and a sink for particles in the $0.02-0.15 \mu \mathrm{m}$ size range (Raes et al., 1995). For particle sizes above about $0.16 \mu \mathrm{m}$ a clear turning point in both the variability and number concentration trend is observed. Between $0.16 \mu \mathrm{m}$ and $0.5 \mu \mathrm{m}$ the particle surface area reaches a maximum and condensation therefore becomes increasingly important for the growth of particles, see Fig. 1. Unlike co- 

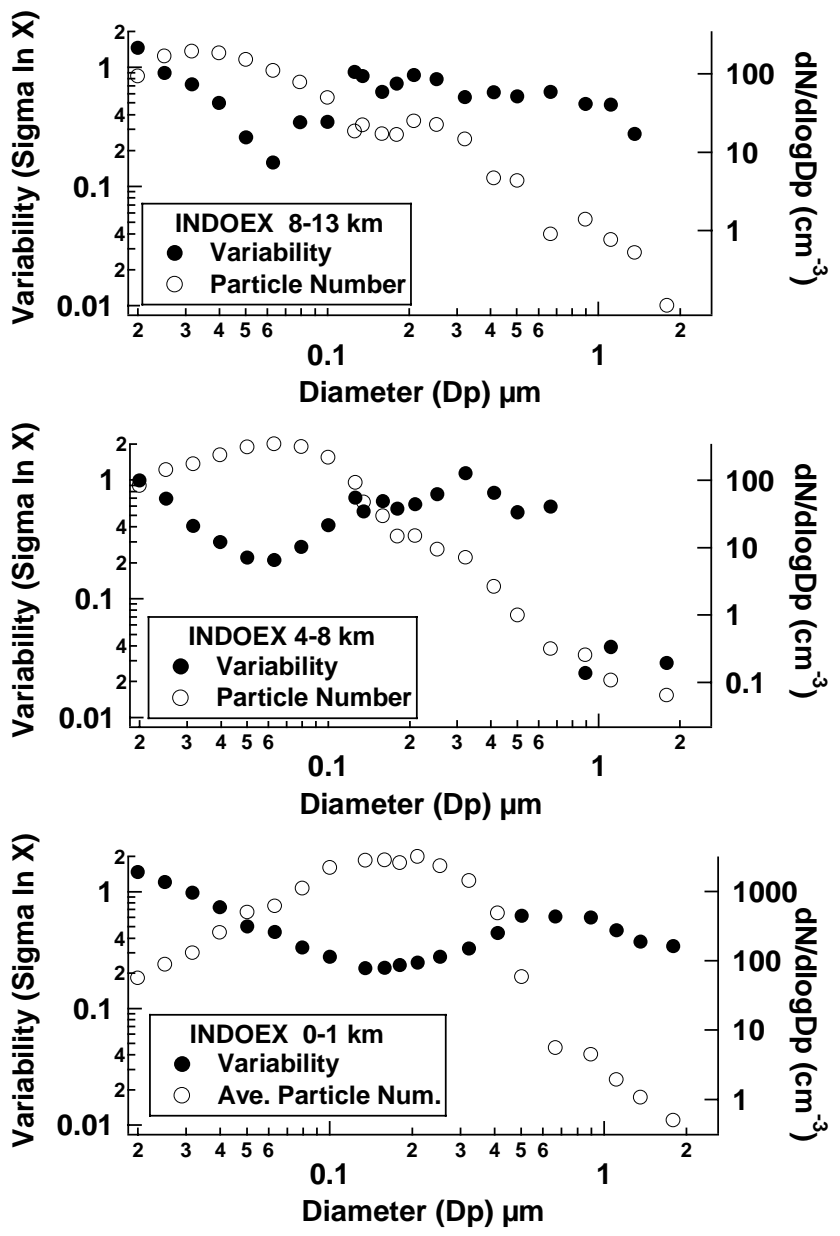

Fig. 2. Measurement variability and average number concentration are plotted as a function of bin size for data collected between (a) 8-13 km, (b) 4-8 km, (c) 0-1 km in February of the INDOEX campaign intensive field phase.

agulation, the strength of the condensation source will be dependent on surface area and accordingly a different trend can be seen in the variability-size relationship.

In contrast to the case above, the local maximum in the number concentration at around $1 \mu \mathrm{m}$, coincides with a maximum in the variability. We postulate that correlation of variability and concentration indicates a direct source of particles of this size range to the atmosphere. As an additional source for some size bins, this would induce more variability in these bins and therefore produce a maximum in the variability and size distribution plot. As these measurements were taken over the northern Indian Ocean we assume these particles to be sea salt. Aerosol size distributions observed in the marine boundary layer over other large ocean surfaces generally show a bi-modal structure, with a minimum at about $0.1 \mu \mathrm{m}$ diameter (e.g. Clarke et al., 1998; Covert et al., 1996; Hoppel et al., 1994), which is indicative for cloud processing. The aerosol size distribution in the marine boundary layer over the northern Indian Ocean, however, does not show such a pronounced bi-modal structure. This is probably due to the high pollution level of the marine boundary layer over the northern Indian Ocean, which masks the effects of rainout and cloud processing (in the polluted air the fraction of aerosols activated as cloud nuclei is small compared to what is potentially available).

We have suggested above that the variability plot may be used to differentiate between particles formed in situ (via coagulation and condensation), and directly injected aerosol based on anticorrelation and correlation with the particle size distribution respectively. Furthermore, the trend in the variability between $0.02-0.1 \mu \mathrm{m}$ has been interpreted as coagulation. We will assess this hypothesis by examining the variability of coagulation and condensation processes with a model below. But first we present how the measured variability trends vary with altitude. Figures $2 \mathrm{a}-\mathrm{c}$ show variability and particle number as a function of bin size for the altitude sections, $8-13 \mathrm{~km}, 4-8 \mathrm{~km}$ and for comparison $0-1 \mathrm{~km}$.

The airmasses between $4-8 \mathrm{~km}$ contained few particles greater than $0.2 \mu \mathrm{m}$. From back trajectory analyses and satellite pictures it was determined that air masses in this altitude range had not had recent contact with surface sources (de Reus et al., 2001). A variability minimum coinciding with a particle number maximum was observed, although at lower particle size than in the $0-1 \mathrm{~km}$ range. A second peak in variability at approximately $0.3 \mu \mathrm{m}$ correlates with the particle size distribution at this particle size. Based on the hypothesis presented previously for the boundary layer, we postulate that particles of this size are directly injected into this altitude range, probably by cloud processes. Such large particles could be either remnants from evaporating cloud particles or interstitial particles transported from the boundary layer into the free troposphere via convection. In both cases the source is discontinuous, thus sporadically providing high particle numbers and hence high variability. Observers on board the research aircraft often noted outflow from convective cells occurring in this altitude range. Very few particles greater than $0.8 \mu \mathrm{m}$ were measured in this altitude range. For many size distributions the number concentration measured at these bins was zero. Although the instrument is functioning correctly the high number of zero values has the effect of reducing the variability, see the three points on the lower right of Fig. 2b.

The uppermost layer $(8-13 \mathrm{~km})$ was found to often contain elevated levels of carbon monoxide, which indicated convective transport of pollutants from the boundary layer to this altitude level (Williams et al., 2002; de Reus et al., 2001). A detailed analysis of the size distributions observed in the uppermost layer $(8-13 \mathrm{~km})$ has been given elsewhere (de Reus et al., 2001). Using a novel combination of backtrajectory information and cloud top temperatures retrieved from satellite images they also concluded that elevated concentrations of nucleation mode particles and $\mathrm{CO}$ were indicative of outflow from convective clouds. In addition it was postulated that ac- 
cumulation mode particles at this level showed indications of cloud processing. The variability of the particles in this size range supports this hypothesis, showing a peak at $0.2 \mu \mathrm{m}$ thus providing a correlation between particle enhancement and variability. A co-incident peak in particle number concentration and variability was observed in all three altitude ranges. A minimum in variability associated with a maximum in particle concentration was also observed at all altitudes, although in the boundary layer this was observed at larger particle sizes $(0.16 \mu \mathrm{m})$ than at higher altitudes (ca. $0.065 \mu \mathrm{m})$.

\subsection{Modelled aerosol variability}

The shape of the size dependent variability gives some clues to which processes control the lifetime of the aerosol in a particular size range. In the following section we make use of a numerical model to compare simulated variability to the observations in order to analyse the relative importance of different processes.

The model describes three processes: new particle formation, coagulation and growth by diffusion of gaseous molecules to pre-existing particles (condensation). The model used in this study is based on a multicomponent coagulation model described in Ström et al. (1992). It is a sectional model with 46 size classes between 0.001 to $35 \mu \mathrm{m}$ diameter and it is using a variable time step. The multi component capability of the model is turned off, but a phenomenological description of new particle formation and a module for aerosol growth by diffusion has been added for this study. Both the new particle formation and the growth by diffusion are related to the concentration of $\mathrm{H}_{2} \mathrm{SO}_{4}$ molecules. The threshold values for new particle formation $\left(10^{6}\right.$ and $\left.10^{7}\right)$ can be viewed as critical supersaturations. This critical level, is held constant during each simulation and hence does not change with temperature or humidity. The surface area is a sink term for the $\mathrm{H}_{2} \mathrm{SO}_{4}$ molecules The oxidation of $\mathrm{SO}_{2}$ by $\mathrm{OH}$ and further reactions provide the source of gaseous $\mathrm{H}_{2} \mathrm{SO}_{4}$. The production rate is written as:

$P_{\mathrm{H}_{2} \mathrm{SO}_{4}}=\left[\mathrm{SO}_{2}\right][\mathrm{OH}] k_{p}$

where $\left[\mathrm{SO}_{2}\right]$ and $[\mathrm{OH}]$ are concentrations in molecules per cubic centimetre, $k_{p}=1.2 \cdot 10^{-12}\left(\mathrm{~s}^{-1} \mathrm{~cm}^{3}\right)$. The $\mathrm{OH}$ concentration is prescribed by a semisinusoidal diurnal variation with a maximum of $3 \cdot 10^{6} \mathrm{~cm}^{-3}$ at noon.

Sulphuric acid molecules may be lost by deposition on pre-existing particles. The sink rate for each bin size $i$, is given by:

$S_{\mathrm{H}_{2} \mathrm{SO}_{4}}=\left[\mathrm{H}_{2} \mathrm{SO}_{4}\right] k s_{i} A_{i} n_{i}$

where $A_{i}$ is the aerosol particle area, $n_{i}$ the number density of aerosol particles, and $k s_{i}$ is the transfer rate of sulphuric acid molecules to pre-existing particles. This rate is given by:

$$
k s_{i}=\frac{1}{\left[\left(\frac{d p_{i}}{D}\right)+\left(\frac{4}{v}\right)\right]}
$$

where $d p_{i}$ is the aerosol diameter, $D$ and $v$ are the sulphuric acid diffusion coefficient and molecular velocity, respectively.

New particles in the model are formed whenever the concentration of sulphuric acid molecules exceeds the fixed threshold value. Molecules in excess of this threshold are assumed to condense into new particles. It is further assumed that water vapour co-condenses in a proportion that yields a particle density of $1.5 \mathrm{~g} \mathrm{~cm}^{-3}$. The new particles are introduced in the smallest bin size and the number of particles is simply given by dividing the condensable mass with the size of that bin which is $1 \mathrm{~nm}$ diameter. Although water vapour is assumed to be part of the particle formation it is not treated elsewhere in the model and hence effects resulting from changes in relative humidity are not simulated. Clearly the treatment of new particle formation in this model is thermodynamically inconsistent. However, this is not a problem in this study since this process could essentially have been included using a prescribed particle production. The formulations are very much simplified, but gives a certain amount of feedback possibilities as the size distribution evolves. It also provides a chance to relate the source terms of particles and condensable vapour to physical parameters.

The initial distribution used in the simulations was given by the observed average size distributions in three altitude ranges, presented in Fig. 2. A series of eight numerical experiments were performed for each altitude level. In the first experiment the size distributions were allowed to age by Brownian coagulation only, and no other processes was turned on. The following three experiments were performed using three different $\mathrm{SO}_{2}$ levels at $0.02,0.2$ and 2 ppbv, respectively. In these simulations $\mathrm{H}_{2} \mathrm{SO}_{4}$ was allowed to form and deposit on pre-existing particles, but new particle formation was turned off. These three experiments were repeated again but this time new particle formation was turned on. The sulphuric acid threshold concentration required in order to activate particle production was $10^{6}$ molecules per cubic centimetre. In the final simulation this threshold was changed to $10^{7} \mathrm{~cm}^{-3}$, and the $\mathrm{SO}_{2}$ concentration was 2 ppbv for the lowest altitude level, and $0.2 \mathrm{ppbv}$ for the two higher altitudes, which are typical $\mathrm{SO}_{2}$ values for the polluted boundary layer.

We are interested in comparing observed variability with the time dependent changes in the aerosol distribution calculated by the numerical model. One way to do this could be to first simulate fairly long time series with different initial conditions. Followed by a random selection of distributions in order to emulate the aircraft measurements and achieve a synthetic variability. However, we choose to limit the simu- 
lations to one day ( 24 hours). The rate of change in number density for each specific bin size was estimated by comparing the initial size distribution with the distribution at the end of the simulation. By using the estimated tendencies one can calculate the time it would take to change the number density by $50 \%$ for each bin size. This time is not only associated with a loss of particles, as the term lifetime would indicate, but may also be a result from a net gain of particles in a particular bin size. In this study we assume that this calculated lifetime is inversely proportional to variability, and hence simply invert the calculated lifetime to compare modelled and measured variability. As the aerosol lifetimes are probably of a similar order to the shorter lived trace gases we might expect a weaker dependence on lifetime. However, as we do not know this dependence for the aerosol case where sources and sinks are very different to trace gases, we follow the intuitive inverse proportionality (variability $=1 /$ lifetime) to determine modelled variability. The matching trends found in the measured variability support this choice. A dependence of 0.5 (variability $=1 /$ lifetime 0.5 ) has been determined as typical of hydrocarbons in the background atmosphere (Erhart et al., 1998; Jobson et al., 1998). We therefore also performed a sensitivity test using the 0.5 dependence and found similar trends and discrepancies in the modelled and measured data to those using as discussed in the model results section below.

\subsection{Model results}

The results from the model calculations are presented here in Figs. 3a-c, for $0-1 \mathrm{~km}, 4-8 \mathrm{~km}$ and $8-13 \mathrm{~km}$, respectively. Each figure shows the calculated variability for each aerosol size associated with: coagulation only; coagulation and condensation; and condensation, coagulation and nucleation, in each case with the measured variability for comparison. The condensation related $\mathrm{SO}_{2}$ mixing ratios chosen for presentation in the altitude ranges $0-1 \mathrm{~km}, 4-8 \mathrm{~km}$ and $8-13 \mathrm{~km}$ were 2, 0.2 and 0.02 ppbv, respectively.

Between $0-1 \mathrm{~km}$, the measured variability trend for particles of smaller than $0.16 \mu \mathrm{m}$, is equivalent to that produced by the model calculation with coagulation alone. For particle sizes $>0.25 \mu \mathrm{m}$, increasing variability with increasing particle diameter condensation becomes more important. Little change in the variability was observed when the concentration of the condensing $\mathrm{SO}_{2}$ was increased from 0.02 to 2 ppbv. There is no strong evidence in measured variability for nucleation in the particle size range presented which according to the model would strongly affect the $20-30 \mathrm{~nm}$ bin sizes. The model differs strongly from the measured variability trend in two ranges, $0.15-0.35 \mu \mathrm{m}$ and $0.7-2.5 \mu \mathrm{m}$ where in both cases the measured variability increases while the modelled variability decreases. This additional variability could arise from additional sources or sinks not accounted for in the model. As suggested above, a source of sea salt particles injected into the boundary layer air could explain the additional variability observed in the higher size range which is not predicted by the model. The discrepancy between 0.15 and $0.35 \mu \mathrm{m}$ could arise from an additional sink provided by interaction with clouds. While particles less than $0.1 \mu \mathrm{m}$ are not expected to be affected by cloud interactions, the efficiency of a cloud sink would gradually increase between 0.1 and $0.5 \mu \mathrm{m}$. A concomitant increase in variability related to this sink from $0.1 \mu \mathrm{m}$ to $0.5 \mu \mathrm{m}$ would therefore be expected if the boundary layer air had come in occasional contact with clouds.

Between 4-8 km, Fig. 3b, the model results show that several of the trends in measured variability can in the be explained by the physical processes included in the model. The model results again indicate that nucleation does not play an important role. For particle sizes of $0.065 \mu \mathrm{m}$ and below, coagulation alone can explain the variability trend, while between 0.065 and $0.3 \mu \mathrm{m}$ variability from diffusional growth by condensation can explain the upward trend in variability with increasing size. Shown in Fig. $3 \mathrm{~b}$ is the calculated variability due to condensation assuming $0.2 \mathrm{ppbv}$ of $\mathrm{SO}_{2}$. At around $0.25 \mu \mathrm{m}$ a discrepancy occurs where the measured variability increases while the modelled decreases. As mentioned before we attribute the increasing variability (and associated maximum in the particle size distribution) to particles directly injected from cloud outflow.

Comparing the measured and model results for the 8$13 \mathrm{~km}$ data also shows no indication that nucleation is affecting the measured variability in this size range. This does not exclude the possibility that nucleation is occurring at this altitude but it suggests that either its effect on the variability is limited to size bins less than $0.002 \mu \mathrm{m}$ or that the model parameterisation of nucleation is not correct. Indeed the small particle data between 0.006 and $0.014 \mu \mathrm{m}$ do show strong evidence of small particle production in this altitude range (de Reus et al., 2001). As the measured variability comes from data collected to a large extent in the vicinity of convective outflow, a complicated variability trend is expected. However the general trend between 0.002 and $0.2 \mu \mathrm{m}$ can be explained by a combination of coagulation and condensation.

\section{Estimating aerosol residence times as a function of size}

The first attempts to measure a general residence time of atmospheric particles were made using radioisotopes as tracers. These attach to aerosol particles and are removed with them during dry deposition and precipitation. Values of the order of 5 days were deduced for midlatitudes from the ratio of short-lived to long-lived radon daughters in surface air (Blifford et al., 1952; Haxel and Schumann 1955). As the decay of radon is essentially a gas to particle conversion process, the decay products attach primarily to a range of aerosol sizes within the accumulation mode and so it is particles within this size range that have an intergrated life- 

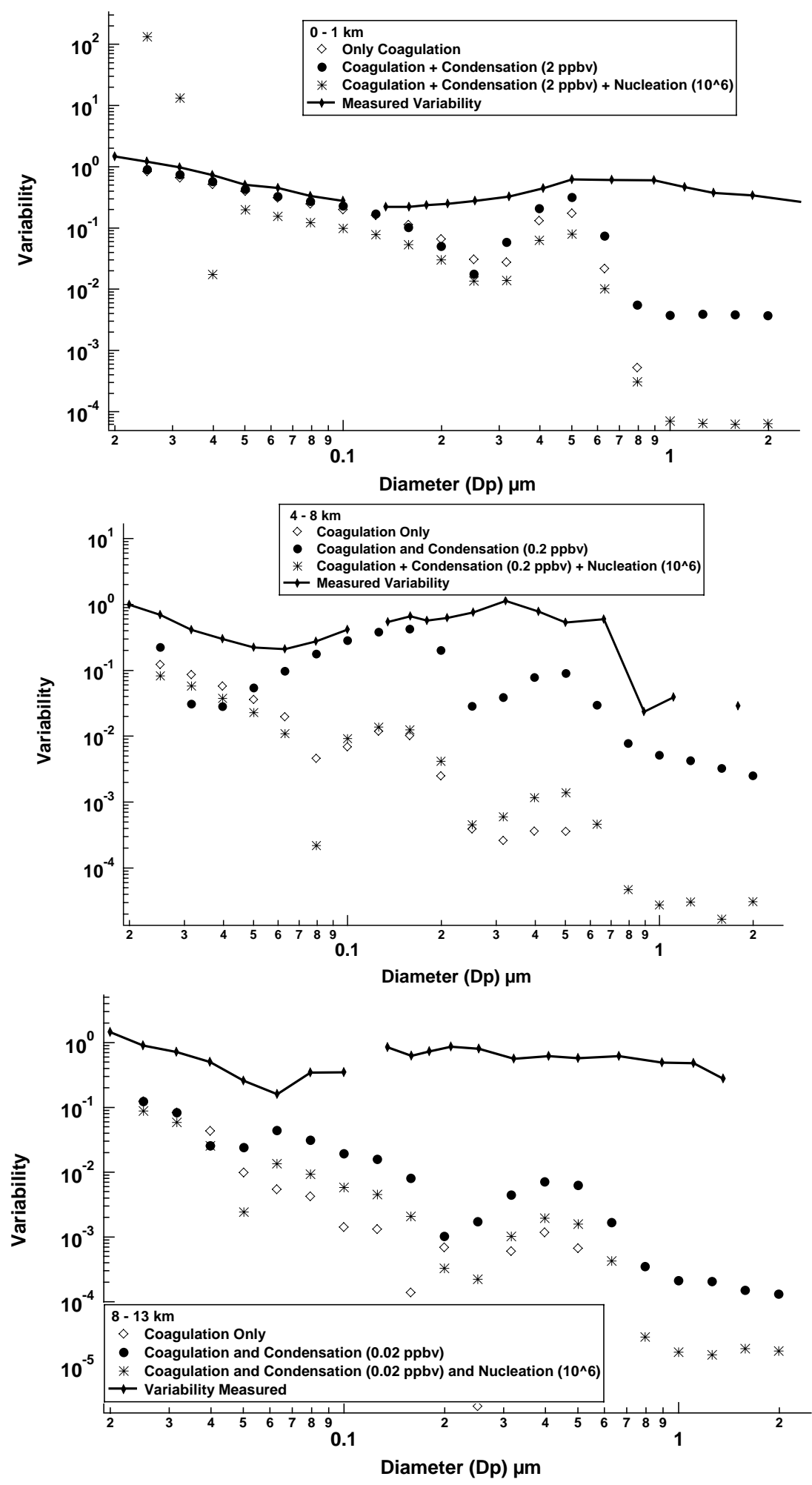

Fig. 3. Comparison of measured variability and of variability predicted by the model for coagulation, coagulation and condensation and coagulation, condensation and nucleation, between (a) $8-13 \mathrm{~km}$, (b) $4-8 \mathrm{~km}$, (c) $0-1 \mathrm{~km}$ in February of the INDOEX campaign intensive field phase. 


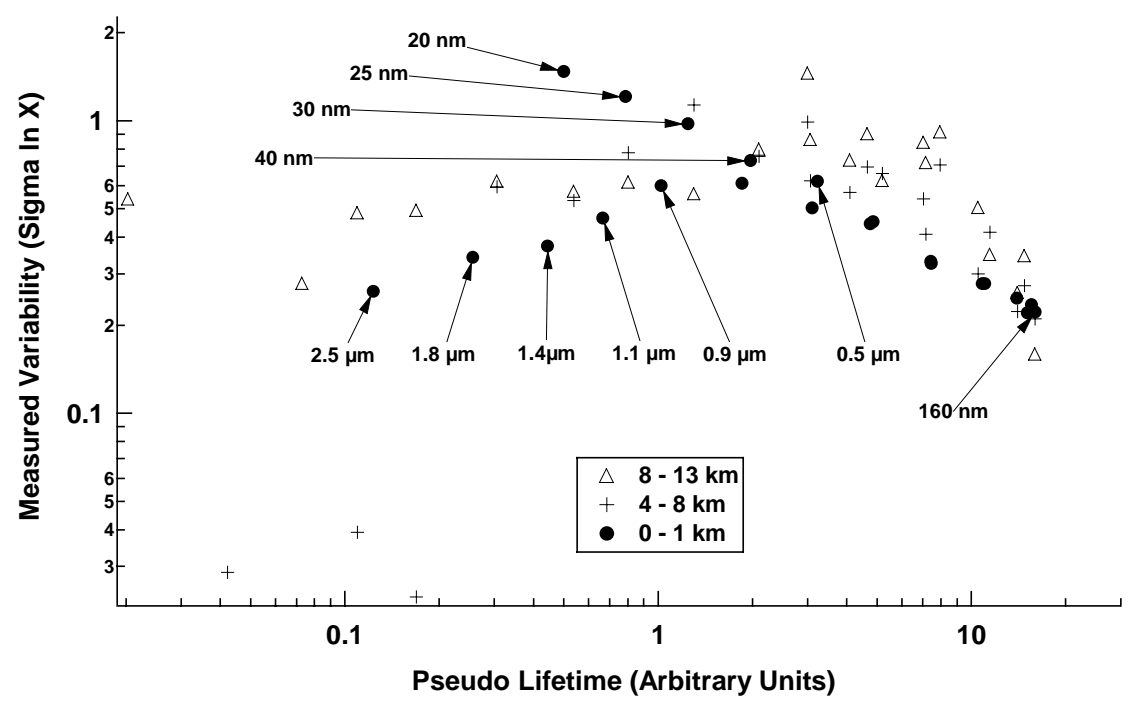

Fig. 4. Measured variability plotted against arbitrary lifetime derived from an adapted version of the Jaenicke expression. Solid circles represent data from $0-1 \mathrm{~km}$, crosses represent data from $4-8 \mathrm{~km}$, and triangles show data from $8-13 \mathrm{~km}$.

time of approximately 5 days. The residence time of tropospheric aerosols as a function of particle size was first examined specifically by Jaenicke $(1978,1980)$. These studies, showed that an empirical residence time function could be derived from published residence time estimates applicable to particles between $10^{-3}$ and $10^{3} \mu \mathrm{m}$.

In this study we attempt to derive residence times for all measured aerosol sizes for the three altitude ranges considered. We base our estimate on the assumption that the variability of particles is to some extent inversely proportional to the lifetime to the power $b$, see Eq. (4). The same relationship has been used successfully in gas phase studies where the coefficient $b$ is used as an indicator of the relative strength of chemical sink and turbulent mixing terms. Values of $b$ close to 1 have been interpreted in gas phase studies as indicating the dominance of the chemical sink which would be expected only in regions remote from sources.

Measured variability (Sigma $\ln \mathrm{X}) \propto T^{-b}$

In order to determine and to interpret the coefficient $b$ for the aerosol case we need to examine the relationship between variability and residence time of a particle in a size bin. We have used a modified version of the empirical expression for residence time given by Jaenicke (1982) shown in Eq. (5) which neglects the effect of wet removal.

$\frac{1}{T} \propto\left(\left(\frac{d p_{i}}{D_{s}}\right)^{2}+\left(\frac{d p_{i}}{D_{s}}\right)^{-2}\right)$

Where $T=$ residence time, $d p_{i}=$ particle diameter, $D_{s}=$ standard diameter (defined by the minimum variability), and $\propto$ is the proportionality symbol. The original expression assumes that a constant standard diameter is applicable to all tropospheric aerosols and that differing extents of wet removal account for the main difference in residence time for this standard diameter of $0.6 \mu \mathrm{m}$. In our study the standard diameter used was taken as the minimum in the measured variability, namely $0.16 \mu \mathrm{m}$ for $0-1 \mathrm{~km}$ data and $0.065 \mu \mathrm{m}$ for both $4-8$ and $8-13 \mathrm{~km}$. In this way we can derive a value for $T$ for each particle size for each altitude dataset. The results of the variability $T$ comparison are shown in Fig. 4.

The absolute value of the residence time $T$ is not important for the derivation of the $b$ coefficient (dependence between variability and residence time) as the coefficient remains the same if the curve is shifted horizontally in Fig. 4. Although the measure of residence time we have used is arbitrary, two distinct trends have emerged: one corresponding to the particles thought to be formed and grow in the atmosphere by in situ physical processes; and one for the particles believed to be injected sporadically into the atmosphere. For $0-1 \mathrm{~km}$ data (shown as filled circles) a well defined anticorrelation of variability and this arbitrary residence time is shown for particles between 0.02 and $0.5 \mu \mathrm{m}$. This inverse dependence of variability lifetime is also observed in trace gas measurements made far from local sources. Particles between $0.5 \mu \mathrm{m}$ and $2.5 \mu \mathrm{m}$ however show a correlation. This may be caused by the increased variability from injected sea salt particles around $1.0 \mu \mathrm{m}$.

Data from the higher altitude datasets, although more scattered, show a similar pattern although anticorrelation is only seen for particles less than $0.15 \mu \mathrm{m}$ and $0.1 \mu \mathrm{m}$ for the 48 and $8-13 \mathrm{~km}$ sections, respectively. Slight correlation is observed for particles $0.2 \mu \mathrm{m}$ and higher between $4-8$ and $8-13 \mathrm{~km}$. For each altitude range we therefore derive two $b$ coefficients for: the anticorrelating section (termed in situ or 


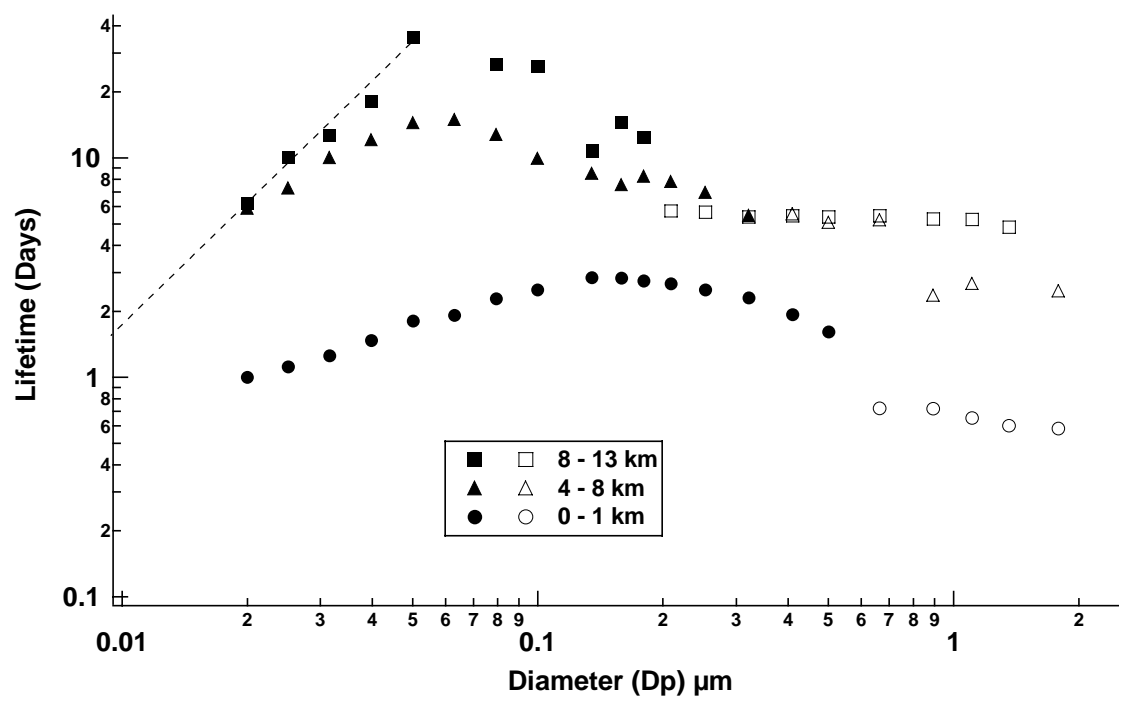

Fig. 5. Lifetime of particles as a function of size for the INDOEX region in February 1999, estimated by fixing the lifetime of the $20 \mathrm{~nm}$ particles to the modelled coagulation lifetime. Filled symbols indicate that the "in situ" $b$ coefficient was used whereas open symbols indicate that the "injected" coefficients were employed. The dashed line shows the extrapolation to 10 nm particle lifetimes for comparison with Schröder et al. (2000).

Table 1. The derived $b$ coefficients from native (in situ formed) particles and non-native (injected) atmospheric particles

\begin{tabular}{lr}
\hline Altitude - Source & $b$ coefficient \\
\hline 0 - 1 km - Native / In situ formed in the atmosphere & $-0.55 \pm 0.02$ \\
0 - 1 km - Non-native / injected & $0.37 \pm 0.04$ \\
4 - 8 km - Native / In situ formed in the atmosphere & $-0.6 \pm 0.07$ \\
4 - 8 km - Non-native / injected & $0.25 \pm 0.39$ \\
8 - 13 km Native / In situ formed in the atmosphere & $-1.01 \pm 0.15$ \\
8 - 13 km Non-native / injected & $0.15 \pm 0.04$ \\
\hline
\end{tabular}

native) and the correlating section (termed non-native or injected particles). The derived values of the $b$ coefficient are given in Table 1. For the in situ particles, the $b$ coefficient is negative and becomes more negative with increasing altitude, whereas for the injected particles the $b$ coefficient is positive and decreases with increasing altitude.

As shown previously, the particles of size $0.020 \mu \mathrm{m}$ in all altitude ranges were affected by one dominant process, coagulation, for which particle residence times may be calculated based on temperature, pressure and number concentration. The absence of other competing processes makes the model estimated residence time most robust in this size range. By fixing the residence time of the $0.020 \mu \mathrm{m}$ particles to the model value and knowing the two $b$ coefficients at each altitude range, the residence times of all size bins are then defined by the measured variability. The derived residence time to particle size relationship is shown in Fig. 5.
Particles measured between $0-1 \mathrm{~km}$ have lifetimes between $0.5-3$ days. Between $4-8 \mathrm{~km}$ and $8-13 \mathrm{~km}$ particle lifetimes range from 4-30 days. In the boundary layer over the Indian Ocean we calculate that the lifetime of particles increases between $0.02 \mu \mathrm{m}$ and $0.165 \mu \mathrm{m}$ from 1-2.5 days. Particle lifetimes decrease between $0.165 \mu \mathrm{m}$ and $2.5 \mu \mathrm{m}$ from 2.5-0.5 days. Above the boundary layer particle lifetimes increase from 6 days at $0.020 \mu \mathrm{m}$ to a maximum lifetime at $0.065 \mu \mathrm{m}$ of 15 days at $4-8 \mathrm{~km}$ and 35 days at 8 $13 \mathrm{~km}$. The accumulation mode particles also have longer lifetimes above the boundary layer, approximately 5 days for the $4-8 \mathrm{~km}$ and $8-13 \mathrm{~km}$ altitude sections examined.

These values for particle lifetimes generally compare well with previous estimations. From the ratio of short-lived to long-lived radon daughters in surface air values on the order of 5 days were deduced (Blifford et al., 1952; Haxel and Schumann, 1955) for midlatitudes. In this study the integrated lifetime of the accumulation mode particles (0.6$2.5 \mu \mathrm{m}$ ) of 3 days in the marine boundary layer and 30 days above boundary layer, is also comparable previous modelled estimates such as: 10-15 days for the tropospheric column in Tropical regions (Balkanski et al., 1993) and of 2-12 days global mean lifetime at $1 \mathrm{~km}$ and $10-35$ days at $8 \mathrm{~km}$ (Giorgi and Chameides, 1986). From a study of sulphur compounds, Rodhe (1978) calculated the atmospheric sulphate turn-over time as $80 \mathrm{~h}$, and later quoted an aerosol residence of between 2-4 days (Rodhe 1999). These numbers are based on budget calculations and are mainly weighted by the boundary layer where most of the aerosol mass is found. For the free troposphere the same study quotes "a few weeks in average" but gives no reference to this number. In a more recent study 
Table 2. The integrated particle ages derived from the calculated lifetimes. Ages derived by extrapolation are marked in greyscale

\begin{tabular}{|c|c|c|c|c|}
\hline Size $(\mu \mathrm{m})$ & $0-1 \mathrm{~km}$ & $4-8 \mathrm{~km}$ & $8-13 \mathrm{~km}$ & Units \\
\hline 0.003 & 885 & 20 & 13 & Seconds \\
\hline 0.005 & 2400 & 285 & 222 & Seconds \\
\hline 0.01 & 2.5 & 2 & 2 & Hours \\
\hline 0.02 & 6.8 & 20 & 24 & Hours \\
\hline 0.05 & 20 & 122 & 180 & Hours \\
\hline 0.08 & 1.3 & 7.9 & 12.7 & Days \\
\hline 0.1 & 1.5 & 9.0 & 15.2 & Days \\
\hline
\end{tabular}

of aviation exhaust in the upper troposphere, the lifetime of particles of about $10 \mathrm{~nm}$ in diameter was estimated as being between "1-2 days or less" to be consistent with typical ambient concentrations measured at the tropopause (Schröder et al., 2000). Extrapolating the line shown in Fig. 5 to $10 \mathrm{~nm}$ particles, shows that the lifetimes presented here are also in general agreement with lifetimes calculated here.

From the lifetime data shown in Fig. 5 it is also possible for each altitude section to derive the age of a given particle (or intergrated time since the particle was formed). For this exercise we assume that what we derive as lifetime is $d \mathrm{Age} / d \log D p$. In order to calculate the integral we fit a lognormal curve and intergrate the area under the curve. Aerosol size distributions are derived analogously from $d N / d \log D p$ vs $D p$ plots. Since from our measurements we derive the lifetime for a particle at a given size, the integral will by definition give the age of the particles, assuming the particle visits all the sizes. Particle ages from the $0-1 \mathrm{~km}, 4-8 \mathrm{~km}$ and $8-13 \mathrm{~km}$ datasets are given in Table 2. Extrapolation to the bin sizes for which we have no measurements $0.001-0.01 \mu \mathrm{m}$ is less certain and these values are marked with greyscale in the table. The derived age of a $0.05 \mu \mathrm{m}(50 \mathrm{~nm})$ particle in the free troposphere is much greater than the same size particle in the boundary layer. However, from the extrapolation to smaller sizes, we tentatively estimate the age of $0.005 \mu \mathrm{m}(5 \mathrm{~nm})$ particles to be greater in the boundary layer than in the free troposphere. The derived ages must be viewed with caution especially in the boundary layer where there is a high concentration of larger particles and hence surface area for condensation. Newly formed particles in the boundary layer may therefore condense directly onto the available larger particles rather than growing through the particle sizes by coagulation which is assumed in the age derivation. The surprisingly high ages derived for $3 \mathrm{~nm}$ particles in the boundary layer indicate that this is indeed probably occuring to some extent. The derived ages can be extected to be more reliable in the free troposphere where the concentrations of large particles are low.

\section{Conclusions}

The use of measurement variability in aerosol studies has been explored in this study for measurements of aerosol size distributions made over the North Indian Ocean in February 1999 as part of the INDOEX experiment. Anti-correlation of the variability with average particle size distribution was observed between $0.02 \mu \mathrm{m}$ and $0.4 \mu \mathrm{m}$ particles, and a variability minimum was observed coincident with the Aitken mode at $0.16 \mu \mathrm{m}$ for data collected between $0-1 \mathrm{~km}$. The anticorrelation was interpreted as indicating that these aerosols were formed via continuous in situ coagulation and condensation, and this size range was not affected by cloud or precipitation sinks. The size range over which this anticorrelation occurred decreased to between $0.020-0.15 \mu \mathrm{m}$ at $4-8 \mathrm{~km}$ where the variability minimum correlating with the Aitken mode was at $0.065 \mu \mathrm{m}$. Between $8-13 \mathrm{~km}$ in a region of convective outflow the anticorrelation was not so evident although a variability minimum at $0.065 \mu \mathrm{m}$ was again observed approximately coincident with the particle concentration mode.

Correlation of the variability with average number concentration was observed centred at $1 \mu \mathrm{m}, 0.200 \mu \mathrm{m}$ and $0.250 \mu \mathrm{m}$ for altitude $0-1,4-8$ and $8-13 \mathrm{~km}$, respectively. These correlations were attributed to the direct and sporadic input of particles to the atmosphere either in the form of sea salt in the boundary layer or from cloud outflow in the two higher altitudes. The extent of correlation between variability and particle concentration is proposed as an aid to interpretation which can indicate whether the aerosol has been formed in situ in the atmosphere or directly injected. Furthermore the $b$ coefficients derived here for the two regimes can be easily compared with future studies to assess the relative effectiveness of physical processes affecting aerosols in different regions of the world.

The variability of the measurements in each size bin may be considered separately from the measured concentrations themselves. We may therefore also use the variability as a additional check for the correct functioning of the instrumentation. Two separate instruments are used to cover the 0.02 $0.1 \mu \mathrm{m}$ and $0.1 \mu \mathrm{m}$ to $2.5 \mu \mathrm{m}$ ranges. The smooth transition 
in variability from $0.02 \mu \mathrm{m}$ to $2.5 \mu \mathrm{m}$, particularly evident in the boundary layer, Fig. 1, indicates that the two instruments, which are based on different physical principles, are functioning consistently.

Comparison of the gradients in measured variability to modelled variability based on a consideration of coagulation, condensation and nucleation, suggested that for particle sizes smaller than the variability minimum coagulation was the dominant process and that nucleation (as described by the model) did not seem to be affecting the variability of the particle sizes measured. In other regions the variability trends may be very different, with condensation or nucleation playing a more important role (Laaksonen). For example, over forested areas biogenic, reactive gases such as terpenes can provide high concentrations of condensable gases to the atmosphere (Kumala et al., 1998). Such gases could condense onto existing particles or cause nucleation (O'Dowd et al., 2002). In order to investigate possible the effects of possible high condensation rates on this dataset two additional sets of simulations were performed where the amount of condensable vapors $\left(\mathrm{H}_{2} \mathrm{SO}_{4}\right)$ were fixed between $1 \times 10^{6}$ to $1 \times 10^{10}$ molecules per $\mathrm{cm}^{3}$ throughout the simulation. In one set of simulations no new particles were allowed, in the other set of simulations the new particle production was prescribed at 144 particles per second. These particles where introduced into the smallest size bins between 1 and $2.5 \mathrm{~nm}$ diameter. Hence, there are no feedbacks between condensable vapours, new particles or the pre-existing size distribution. The results from these simulations results (not shown) showed that when the condensable vapours are increased to a point where the accumulation mode is significantly influenced, this also affects the smaller particles in the Aitkenmode. The conclusion is that simply increasing the amount of condensable vapors and/or changing their temporal variation can not make the calculations fit the observations better. As expected in this case-study over the remote Indian Ocean there was no evidence of reactive species such as terpenes in high concentration, and based on our comparison of model and measured variability trends no evidence that condensation played a significant role between $0.02-0.16 \mu \mathrm{m}$ in the boundary layer (Fig. 3a) or between $0.02-0.05 \mu \mathrm{m}$ in the 4-8 km range (Fig. 3b).

An interaction of the airmasses with clouds was also suggested from the observed discrepancy between modelled and measured variability. Rainout and washout are processes that act on aerosols of certain sizes, within time scales that are shorter than the scale of the aerosol age or lifetime. This will introduce regions with higher or lower number densities of these aerosols that we then observe as variability. An important process is of course the time scale it takes for the atmosphere to recover from such an intermittent sink as this will temper the effect on the variability. Relative to rainout and washout, dry deposition is not very effective and influences only a very small fraction of the atmospheric aerosol. The aerosol modelling in this study has been kept deliber- ately simple. As a simplification of the real world the model does not include all processes that are of importance in fully simulating the aerosol dynamics (e.g. in cloud processes and ocean sources). It is in principle feasible to perform this exercise using a 3-D model, making a large number of longer simulations to emulate the sampling from aircraft, but this would necessitate a large number of assumptions to be made and is beyond the scope of this study. This paper presents a new way of analysing aerosol measurement with model data in a case study. It is hoped that other groups with more advanced models will be interested to examine these effects in further detail.

In the case of the $b$ factor from the in situ formed particles it is possible to ascribe a meaning to the value of $b$. We suggest that the $b$ factor is indicative of the relative role of self coagulation. This means that if progressive particle growth through coagulation were the only process affecting newly formed aerosol we would expect high values of $b$ (approaching 1). Where larger particles are abundant, such as in the boundary layer, the newly formed particles may instead interact directly with the larger particles reducing the effectiveness of self coagulation. The presence of larger particles has the effect that the lifetime of the small particles with respect to coagulation becomes longer and the lifetime of the larger particles becomes shorter. This can be seen in the residence time and ages presented in Fig. 5 and Table 2. It could be argued that the $b$ factor would be influenced by new particle formation, the extra source of small particles and hence variability would act to steepen the gradient $b$. However in the measured variability we see no evidence of particle production in the $0.02 \mu \mathrm{m}(20 \mathrm{~nm})$ bin contrary to the model predictions. This is surprising as from the relatively low lifetimes of $0.05 \mu \mathrm{m}$ particles in the boundary layer compared to the free troposphere we can conclude that the formation of new particle mass is significant and that nucleation is occurring. One possible explanation for the discrepancy between modelled and measured variability in this range can be given. Particles in the model are formed in stochastic events or bursts whenever the concentration of sulphuric acid molecules exceeds a certain threshold value. If instead, particle production occurs at a lower but continuous rate, then the effect of the particle production on variability may be confined to bin sizes below the lowest measured size of $0.02 \mu \mathrm{m}$.

Using a novel approach, lifetimes of individual aerosol size bins have been calculated based on the measured variability. Generally higher lifetimes were observed at higher altitudes in agreement with previous estimates (Raes et al., 2000 and references therein). Aerosols $0.065 \mu \mathrm{m}$ in size have lifetimes comparable to $\mathrm{CO}$ in the upper atmosphere, approximately 1 month and can be transported on a hemispheric scale. The same size aerosol has a lifetime one order of magnitude less in the boundary layer and therefore aerosol produced in the boundary layer will not be transported far from the source regions. From the calculated residence times and ages we conclude that following formation, $0.001 \mu \mathrm{m}$ 
particles grow to $0.01 \mu \mathrm{m}$ fastest in the free troposphere, but further growth from $0.01 \mu \mathrm{m}$ to $0.1 \mu \mathrm{m}$ is fastest in the boundary layer.

Acknowledgements. The authors thank the staff of the Delft University of Technology, the pilots, engineers and crew of the Citation and the Maldives Meteorological Service for their able assistance and professionalism. Prof. G. Harris is also thanked for his insightful comments. Thanks are due to all INDOEX participants for the informative workshop discussions.

\section{References}

Balkanski, Y. J., Jacob, D. J., and Gardner, G. M.: Transport and residence times of tropospheric aerosols inferred from a global model 3-dimensional simulation of Pb-210, J. Geophys. Res.Atmos., 98, D11, 20 573-20 586, 1993.

Blifford, I. H., Lockhart, L. B., and Rosenstock, H. B.: On the natural radioactivity in the air, J. Geophys. Res., 57, 499-509, 1952.

Charlson, R. J., Schwartz, S. E., Hales, J. M., Cess, R. D., Coakley, J. A., H. J. E., and Hofmann, D. J.: Climate forcing by anthropogenic aerosols, Science , 423-429, 1992.

Clarke, A. D., Varner, J. L., Eisele, F., Mauldin, R. L., Tanner, D., and Litchy, M.: Particle production in the remote marine atmosphere: Cloud outflow and subsidence during ACE 1, J. Geophys. Res., 103, 16397-16409, 1998.

Covert, D. S., Kapustin, V. N., Bates, T. S., and Quinn, P. K.: Physical properties of marine boundary layer aerosol particles of the mid-Pacific in relation to sources and meteorological transport, J. Geophys. Res., 101, 6919-6930, 1996.

de Reus, M., Krejci, R., Williams, J., Fischer, H., Scheele, R., and Ström, J.: Vertical and horizontal distributions of the aerosol number concentration and size distribution over the northern Indian Ocean, J. Geophys. Res., 106, 28 692-28 641, 2001.

de Reus, M., Ström, J., Curtius, J., Pirjola, L., Vignatti, E., Arnold, F., Hansson, H.-C., Kulmala, M., Lelieveld, J., and Raes, F.: Aerosol production and growth in the upper free troposphere, J. Geopys. Res., 105, 24751-24 762, 2000.

Ehhalt, D. H., Rohrer, F., Wahner, A., Prather, M. J., and Blake, D.: On the use of hydrocarbons for the determination of tropospheric OH concentrations, J. Geophys. Res., 103, 18 981-18 997, 1998.

Graedel, T. and Crutzen, P. J.: Atmospheric Change, An Earth System Perspective, W.H. Freeman and Company, New York, 1993.

Giorgi, F. and Chameides, W. L: Rainout lifetimes of highly solubleaerosols and gases as inferred from simulation with a general circulation model, J. Geophys. Res. 91, 14 367-14 376, 1986.

Haxel, U. and Schumann, G.: Selbstreinigung der Atmosphäre, Z. Phys., 142, 127-132, 1955.

Hinds, W. C.: Aerosol Technology, John Wiley and Sons, New York, pp. 146, 1982.

Hoppel, W. A., Frick, G. M., Fitzgerald, J. W., and Larson, R. E.: Marine boundary layer measurements of new particle formation and the effects nonprecipitating clouds have on aerosol size distribution, J. Geophys. Res., 99, 14 443-14 459, 1994.

Houghton, J. T.: IPCC (Intergovernmental Panel on Climatic Change), Cambridge University Press, Cambridge UK, pp. 572, 1996.
Iyengar, G. R., Prasad, V. S., and Ramesh, K. J.: Circulation characteristic associate with Inter Tropical Convergence Zone during northern winter, Current Science, 76, 903-906, 1999.

Jaecker-Voirol, A. and Mirabel, P.: Heteromolecular nucleation in the sulphuric acid-water system, Atmos. Environ., 23, 20532057, 1989.

Jaenicke, R.: Über die Dynamik atmsphärischer Aitken-teilchen, Ber. Bunsenenes Phys. Chem., 82, 1198-1202, 1978.

Jaenicke, R.: Atmospheric Aerosol and Climate, J. Aerosol Sci., 11, 577-588, 1980.

Jaenicke, P.: Physical aspects of the atmospheric aerosol, Chemistry of the Unpolluted Troposphere, (Eds) Georgii, H. W. and Jaeschke, W., D. Riedel Publishing, 341-373, 1982.

Jobson, B. T., McKeen, S. A., Parrish, D. D., Fehsenfeld, F. C., Blake, D. R., Goldstein, A. H., Schauffler, S. M., and Elkins, J. W.: Trace Gas Mixing Ratio Variability vs. Lifetime in the Troposphere and Stratosphere - Observations, J. Geophys. Res., 104, D13, 16 091-16113, 1999.

Jobson, B. T., Parrish, D. D., Goldan, P., Kuster, W., Fehsenfeld, F. C., Blake, D. R., Blake, N. J., and Niki, H.: Spatial and Temporal Variability Of Nonmethane Hydrocarbon Mixing Ratios and Their Relation to Photochemical Lifetime, J. Geophys. Res. Atmos., 103 , 13 557-13 567, 1998.

Jokinen, V. and Mäkela, J. M.: Closed loop arrangement with critical orifice for DMA sheath/excess flow system, J. Aerosol. Sci., 28, 643-648, 1997.

Junge, C. E.: Residence time and variability of tropospheric trace gases, Tellus, 16, 477-488, 1974.

Koch, S., Winterhalter, R., Uherek, E., Kolloff, A., Neeb, P., and Moortgat, G. K.: Formation of new particles in the gas-phase ozonolysis of monoterpenes Atmos. Env., 34, 23, 4031-4032, 2000.

Korhonen, P., Kulmala, M., Laaksonen, A., Viisanen, Y., McGraw, R., and Seinfeld, J. H.: Ternary nucleation of $\mathrm{H}_{2} \mathrm{SO}_{4}, \mathrm{NH}_{3}$ and $\mathrm{H}_{2} \mathrm{O}$ in the atmosphere, J. Geophys. Res., 104, 26 349-26354, 1999.

Kulmala, M., Laaksonen, A., and Pirjola, L.: Parameterizations for sulphuric acid/water nucleation rates, J. Geophys. Res., 103, 8301-8303, 1998.

Kulmala, M., Toivonen, A., Mäkelä, J., and Laaksonen, A.: Analysis of the growth of nucleation mode particles observed in Boreal forest, Tellus. 50B, 449-462, 1998.

Kulshrestha, U. C., Jain, M., Mandal, T. K., Gupta, P. K., Sarkar, A. K., and Parashar, D. C.: Measurements of acid rain over the Indian Ocean and surface measurements of atmospheric aerosols at New Delhi during INDOEX pre-campaigns, Current Science, 76, 968-972, 1999.

Laaksonen, A.: Interactive comment given to this paper in ACPD, Atmos. Chem. Phys. Discuss., 2, S30-S31, 2002.

Lelieveld, J., Crutzen, P. J., Andreae, M. O., Cass, G., Dickerson, R. R., Fischer, H., Gouw, J. A. D., Hansel, A., Kley, D., Laat, A. T. J. D., Lal, S., Lawrence, M. G., Lobert, J., Mitra, A. P., Novakov, T., Oltmans, S. J., Rodhe, H., Smit, H. G. J., Williams, J., and Ramanathan, V.: Large impact of southeast Asian air pollution: Results from the Indian Ocean Expriment, Science, 291, 10311036, 2001.

McGregor, G. R. and Nieuwolt, S.: Tropical Climatology, John Wiley and Sons, Chicester, England, 1998.

O’Dowd, C., Aalto, P., Hämeri, K., Kulmala, M., and Hoffmann, T.: 
Aerosol formation: atmospheric particles from organic vapours, Nature, 416, 497-498, 2002.

Raes, F., Wilson, J., and van Dingen, R.: Aerosol dynamics and its implication for global aerosol climatology, in: Aerosol Forcing of Climate, (Eds) Charlson, R. J. and Heintzenberg, J., Wiley, New York, 1995.

Raes, F., van Dingenen, R., Vignati, E., Wilson, J., Putaud, J.-P., Seinfeld, J. H., and Adams, P.: Formation and cycling of aerosols in the global troposphere, Atmos. Env., 34, 4215-4240, 2000.

Ramanathan, V.: Trace-Gas Greenhouse Effect and Global Warming - Underlying Principles and Outstanding Issues - Volvo Environmental Prize Lecture - 1997, Ambio, 27, 187-197, 1998.

Rodhe, H.: Budgets and turn-over times of atmospheric sulfur compounds, Atmos. Env., 12, 671-680, 1978.

Rodhe, H.: Human impact on the atmospheric sulfur balance, Tellus, 51A-B, 110-122, 1999.

Schröder, F. and Ström, J.: Aircraft measurements of sub micrometer aerosol particles $(>7 \mathrm{~nm})$ in the midlatitude free troposphere and tropopause region, Atmos. Res., 44, 333-356, 1997.

Schröder, F., Brock, C. A., Baumann, R., Petzhold, A., Busen, R., Schulte, P., and Fiebig, M.: In situ studies on volatile jet exhaust particle emissions: Impact of sulfur content and enviromental conditions on nuclei mode aerosols. J. Geophys. Res., 105, D15, 19941-19954, 2000.

Ström, J., Okada, K., and Heintzenberg, J.: On the state of mixing of particles due to Brownian coagulation, J. Aerosol. Sci., 23, 467-480, 1992.

Verver, G., Zachariasse, M., Sikka, D., and Stossmeister, G.:
Overview of the meteorological conditions and atmospheric transport processes during the INDOEX IFP 1999, J. Geophys. Res., 106, 28 399-28 414, 2001.

Wienhold, F. G., Fischer, H., Hoor, P., Wagner, V., Königstedt, R., Harris, G. W., Anders, J., Grisar, R., Knothe, M., Riedel, W. J., . Lübken, F.-J, and Schilling, T.: TRISTAR - a tracer in situ TDLAS for atmospheric research, Applied Physics, B, 411-417, 1998.

Williams, J., Fischer, H., Harris, G. W., Crutzen, P. J., Hoor, P. J., Hansel, A., Holzinger, R., Warneke, C., Lindinger, W., Scheeren, B., and Lelieveld, J.: The variability-lifetime relationship for organic trace gases: a novel aid to compound identification and estimation of HO concentrations, J. Geophys. Res., 105, 20473 $20486,2000$.

Williams, J., Fischer, H., Hoor, P., Pöschl, U., Crutzen, P. J., Andreae, M. O., and Lelieveld, J.: Influence of the tropical rain forest on atmospheric $\mathrm{CO}$ and $\mathrm{CO}_{2}$ as measured by aircraft over Surinam, South America, Chemosphere, 3, 157-170, 2001a.

Williams, J., Gros, V., Bonsang, B., and Kazan, V.: The HO cycle in 1997 and 1998 over the southern Indian Ocean empirically derived from CO, Radon and hydrocarbon measurements made at Amsterdam Island, J. Geophys. Res. 106, D12, 12 719-12 725, 2001b.

Williams, J., Fischer, H., Wong, S., Crutzen, P. J., Scheele, M. P., and Lelieveld, J.: Near Equatorial $\mathrm{CO}$ and $\mathrm{O}_{3}$ profiles over the Indian Ocean during the winter monsoon: high $\mathrm{O}_{3}$ levels in the middle troposphere and interhemispheric exchange, J. Geophys. Res., INDOEX special issue 2, in press, 2002. 